Wilfrid Laurier University

Scholars Commons @ Laurier

$11-2-1998$

\title{
Fluorescence Analysis for Multi-Site Aluminum Binding to Natural Organic Matter
}

D. Scott Smith

Wilfrid Laurier University, ssmith@wlu.ca

James R. Kramer

McMaster University

Follow this and additional works at: https://scholars.wlu.ca/chem_faculty

Part of the Chemistry Commons

\section{Recommended Citation}

Smith, DS, Kramer, JR. Fluorescence analysis for multi-site aluminum binding to natural organic matter. Environment International 1999;25:295-306.

This Article is brought to you for free and open access by the Chemistry at Scholars Commons @ Laurier. It has been accepted for inclusion in Chemistry Faculty Publications by an authorized administrator of Scholars Commons@Laurier. For more information, please contact scholarscommons@wlu.ca. 


\title{
FLUORESCENCE ANALYSIS FOR MULTI-SITE ALUMINUM BINDING TO NATURAL ORGANIC MATTER
}

\author{
D. Scott Smith and James R. Kramer \\ McMaster University, School of Geography and Geology, Hamilton, ON, L8S 4M1, Canada
}

EI 9808-192 M (Received 26 August 1998; accepted 2 November 1998)

\begin{abstract}
Natural organic matter (NOM) samples isolated from different water sources in Norway were compared using their fluorescence properties. Fluorescence surfaces were observed at $\mathrm{pH} 4.36$ and deconvoluted using SIMPLISMA (Windig and Guilment 1991). There were a total of seven different fluorophores observed for these samples and each sampling site had between four and six of the fluorescent components. These components were observed to bind $\mathrm{Al}$ during titrations at the same $\mathrm{pH}$. Multiresponse titration curves were fit using the method of Smith and Kramer (1998) and most of the binding strengths are similar to values for Suwannee River fulvic acid (logK' between 4.8 and 5.5$)$, but there are strong sites $\left(\log K^{\prime}=7\right)$ and weak sites $\left(\log K^{\prime}\right.$ between 3 and 4$)$ also observed. Results depended on the isolation method used; reverse osmosis and low pressure evaporation yielded different values but with no consistent trends. 01999 Elsevier Science Ltd
\end{abstract}

\section{INTRODUCTION}

Natural organic matter (NOM) is an important ligand for metals in aqueous systems. The determination of metal binding constants with NOM is difficult because NOM is a complex, heterogeneous mixture of potential binding sites. Often, metal binding constants are determined by titration of NOM with metal. The result is a titration curve that can be fit to a speciation model. This method is limited in that a single curve is used to determine all of the speciation parameters. The resolution of the method can be improved if multiple titration curves are fit simultaneously. This paper utilizes a multiresponse fluorescence method to determine binding constants for aluminum with NOM samples isolated as part of the NOM-typing project.

Fluorescence is ideally suited for fitting multiple titration curves for metal-NOM interactions. This is because wavelengths can be selected from the excitation vs. emission fluorescence surface that correspond to single components. The result is component-specific speciation. In previous work (Smith and Kramer 1998; Luster et al. 1996), these wavelengths were arbitrarily selected based on maximum fluorescence change. In this paper, spectral deconvolution is used to define a minimum number of components and their position. This is accomplished using SIMPLISMA (Windig and Guilment 1991), which has the added advantage that it yields spectral information about the components. The binding sites can be compared to model compounds in terms of binding strength as well as excitation and emission wavelengths.

It is important to understand $\mathrm{Al}$ complexation by NOM because $\mathrm{Al}$ is a potentially toxic metal (Nieboer et al. 1995; Marschner 1995; Cronan and Grigal 1995), but the toxicity of $\mathrm{Al}$ is speciation-dependent (Parent et al. 1996). Aluminum is of particular interest because environmental acidification increases the amount of 
available $\mathrm{Al}$ due to increased solubility of $\mathrm{Al}$ minerals at lower $\mathrm{pH}$. In addition, $\mathrm{Al}$ is often added as alum (aluminum sulphate) during drinking water treatment, and could still complex with residual NOM.

\section{EXPERIMENTAL METHOD}

NOM samples were obtained as part of the international NOM-typing project (Chairman E. Gjessing, Agder College, Norway); both reverse osmosis (RO) and low temperature vacuum evaporative residues (EV) isolates were studied. A description of the sampling sites and basic characteristics of the raw waters as well as the isolates is given by Gjessing et al. (1998). In this paper, the samples will be designated by isolation method (RO or EV) and by sampling site number, where the numbering scheme for the May (1996) samples is as follows: Trehørningen is NOM-1, Hellerudmyra is NOM-2, Aurevann is NOM-3, Maridalsvann is NOM-4, Birkenes is NOM-5, Humex is NOM-6, Gjerstad (limed) is NOM-7, Gjerstad (unlimed) is NOM-8, and for October (1996) Helerudmyra is referred to as NOM-9. In addition, Suwannee River fulvic acid is referred to as NOM-10. The samples were obtained in powdered form and solutions were diluted to the required volume using MilliQ water $(>18 \Omega)$. Suwannee River fulvic acid was obtained from the International Humic Substance Society which used isolation by adsorption on XAD resins. Aluminum stock solutions were prepared from aluminum nitrate. All glassware was cleaned using a $10 \%$ nitric acid bath overnight, followed by repeated rinses with MilliQ water.

The fluorometer used was a Perkin-Elmer MPF-44. The excitation and emission monochrometers were automated and computer-controlled. Data acquisition was computer-controlled and an entire surface could be acquired in $2 \mathrm{~h}$. The fluorometer was operated in ratio mode to correct for variations in excitation source intensity. The excitation and emission slits were both set at $20 \mathrm{~nm}$ to increase sensitivity for working with dilute solutions. The sample cell was replaced with a Bausch and Lomb UV-transparent cuvette of sufficient volume $(60 \mathrm{~mL})$ to allow titrations to be performed directly in the path of the light. Magnetic stirring was performed throughout the titrations. This setup was found to yield the same results as a traditional quartz cell, but had the added advantage of not needing a pump to introduce the sample to the cuvette. The $\mathrm{pH}$ electrode could be placed directly in the sample while fluorescence was measured. A Cole-Palmer glass combination electrode was used for $\mathrm{pH}$ measurements.
Initial experiments involved measuring the excitation vs. emission fluorescence surface for the $\mathrm{RO}$ samples. This was done at a $\mathrm{pH}$ of $4.36 \pm 0.03$ for each sample; $\mathrm{pH}$ was adjusted, after each addition of titrant, with dilute nitric acid or dilute sodium hydroxide as necessary. The ionic strength was set at $0.1 \mathrm{~mol} / \mathrm{L}$ using potassium nitrate. The isolate concentration was selected to yield a final dissolved organic carbon concentration around 5 to $10 \mathrm{mg} \mathrm{C} / \mathrm{L}$. At these concentrations, inner filter effects were negligible, except absorbance of $\mathrm{KNO}_{3}$ (around $250 \mathrm{~nm}$ ) was corrected using the method of Tucker et al. (1992). Surfaces were obtained by measuring every $10 \mathrm{~nm}$ in both excitation and emission in the range 250-500 for excitation and 380-650 for emission. The fluorescence of the sample with $50 \mu \mathrm{mol} / \mathrm{L}$ additional aluminum was also measured at the same $\mathrm{pH}$.

After the RO fluorescence surfaces were measured, they were deconvoluted using SIMPLISMA as described below. Fluorescence surfaces were not measured or deconvoluted for EV samples because Blaser et al. (1999) found no significant differences between fluorescence surfaces for EV vs. RO samples. Wavelengths were selected corresponding to each component and these wavelengths were monitored during a titration of aluminum at $\mathrm{pH} 4.36 \pm 0.03$. These wavelengths were selected at maximum fluorescence for each component. In general,three repeat measurements were obtained for each addition of $\mathrm{Al}$ and at least 10 titration points were recorded in the range of 0 to $100 \mu \mathrm{mol} / \mathrm{L}$ added Al. After each addition of titrant, the $\mathrm{pH}$ was adjusted using dilute acid and base as needed. An equilibration time of fifteen minutes was allowed between additions of titrant. Preliminary studies on these samples showed that fluorescent changes after this time are negligible. The titration was halted when the titration curves were observed to be flattening. The initial concentration of aluminum was taken from total aluminum concentrations measured by Gjessing et al. (1999).

\section{DATA ANALYSIS}

All data analysis was performed using Matlab ${ }^{\mathrm{TM}}$ (The MathWorks, MA, USA). Descriptions are given below for the spectral deconvolution method for fluorescence surfaces and for the multiresponse parameter fitting method used.

\section{Spectral deconvolution}

For most fluorophores, the shape of the excitation and emission spectrum is independent of emission and 
excitation wavelength, respectively (Guilbault 1973). If this is assumed to be true, then spectral deconvolution can be performed on fluorescence excitation vs. emission surfaces in order to isolate the components. This has in fact been done for mixtures of polycyclic aromatic hydrocarbons (Dalibart 1997) using factor analysis. To the authors' knowledge, this has never been done to NOM fluorescence surfaces before.

Spectral deconvolution was performed using the SIMPLISMA method of Windig and Guilment (1991). This method involves selecting pure variables that are proportional in intensity to only one component of the mixture. Once this is done, a matrix equation is solved to determine the pure spectra and concentrations of each component. In the SIMPLISMA package, this is done using least squares fitting, which can result in negative concentrations. This problem was addressed by modifying the SIMPLISMA code so that constrained non-negative least squares optimization, as implemented by Matlab (Grace 1992), was used to solve the matrix equation.

In order to deconvolute the surfaces, the Rayleigh lines corresponding to scatter at the excitation wavelength and twice the excitation wavelength had to be removed. This was accomplished using a cubic spline fit to replace fluorescence observations within the Rayleigh line. This was done to allow input into SIMPLISMA, because SIMPLISMA can not handle data with missing observations. Interpolated values were never used in parameter fitting.

\section{Multiresponse parameter fitting}

The fitting method used was essentially the method of Smith and Kramer (1998), but with some modifications. This method is basically a multiresponse version of the traditional Ryan-Weber equation (Ryan and Weber 1982). The fluorescence at any excitation and emission wavelength pair is a function of the concentrations of the fluorescent species. If the fluorescence as a function of fluorophore concentration is assumed to be linear, which is a good assumption in dilute solution (Guilbault 1973), then the fluorescence at any excitation/emission wavelength pair, as a function of total metal, $M_{T}$, can be written:

$$
f\left(M_{T}\right)=\sum_{j=1}^{m}\left(e_{j} C_{j}\left(M_{T}\right)\right)+\xi
$$

for $\mathrm{m}$ different fluorescent species with proportionality constant $e_{j}$ and concentration $C_{j}$, where $C_{j}$ is a function of $\mathrm{M}_{\mathrm{T}}$. The term $\xi$ includes all the experimental variation, which is assumed to have a Gaussian distribution. This equation can be rewritten in matrix form for $p$ additions of metal as:

$$
F=C E+\Xi
$$

where,

$F$ is a $p \times q$ matrix containing a column of length $p$ for $q$ different sets of fluorescence observations;

$\mathrm{C}$ is a $\mathrm{p} \times \mathrm{m}$ matrix with a column of concentrations for each of the $m$ fluorescent species; and

$\mathrm{E}$ is a $\mathrm{m} \times \mathrm{q}$ matrix containing a proportionality constant for each species at each set of observation wavelengths.

The calculations are simplified by assuming that wavelength pairs can be found, for each component, at which fluorescence depends on the speciation only at that component. These wavelengths are determined using SIMPLISMA as described above. The fluorescence of component $n$, of a total of $\mathrm{N}$ components, can now be written:

$$
F_{n}=C_{n}(\theta) E_{n}+\Xi_{n}
$$

where the matrices have the same meaning and dimensions as in the general form of Eq. 2, except now $\mathrm{q}$ is equal to one. The problem then becomes fitting $\mathrm{N}$ simultaneous equations of the form given in Eq. 3 to parameters that describe the speciation given in each of the $C_{n}$ matrices. The parameters are common to all $N$ sets of observations and are collected in the vector $\theta$. The parameters include $\mathrm{N}$ conditional stability constants $\left(\mathrm{K}^{\prime}\right)$ and $\mathrm{N}$ ligand concentrations $\left(\mathrm{L}_{\mathrm{T}}^{\prime}\right)$. In this study, the speciation model consists of a mixture of ligands forming one to one complexes with Al. Experiments are performed at fixed $\mathrm{pH}$ so acidity constants can be ignored.

In addition to the nonlinear speciation parameters in $\theta$, there are also two linear parameters for each component. These are contained in the matrix $E_{n}$, and these correspond to fluorescence of free and Al-bound ligand. In previous work (Smith and Kramer 1998), the method of van Stokkum et al. (1993) was used to fit these parameters using $\mathrm{QR}$ decomposition at each iteration of the search for best nonlinear parameters. $\mathrm{QR}$ decomposition is a matrix method used to reduce 

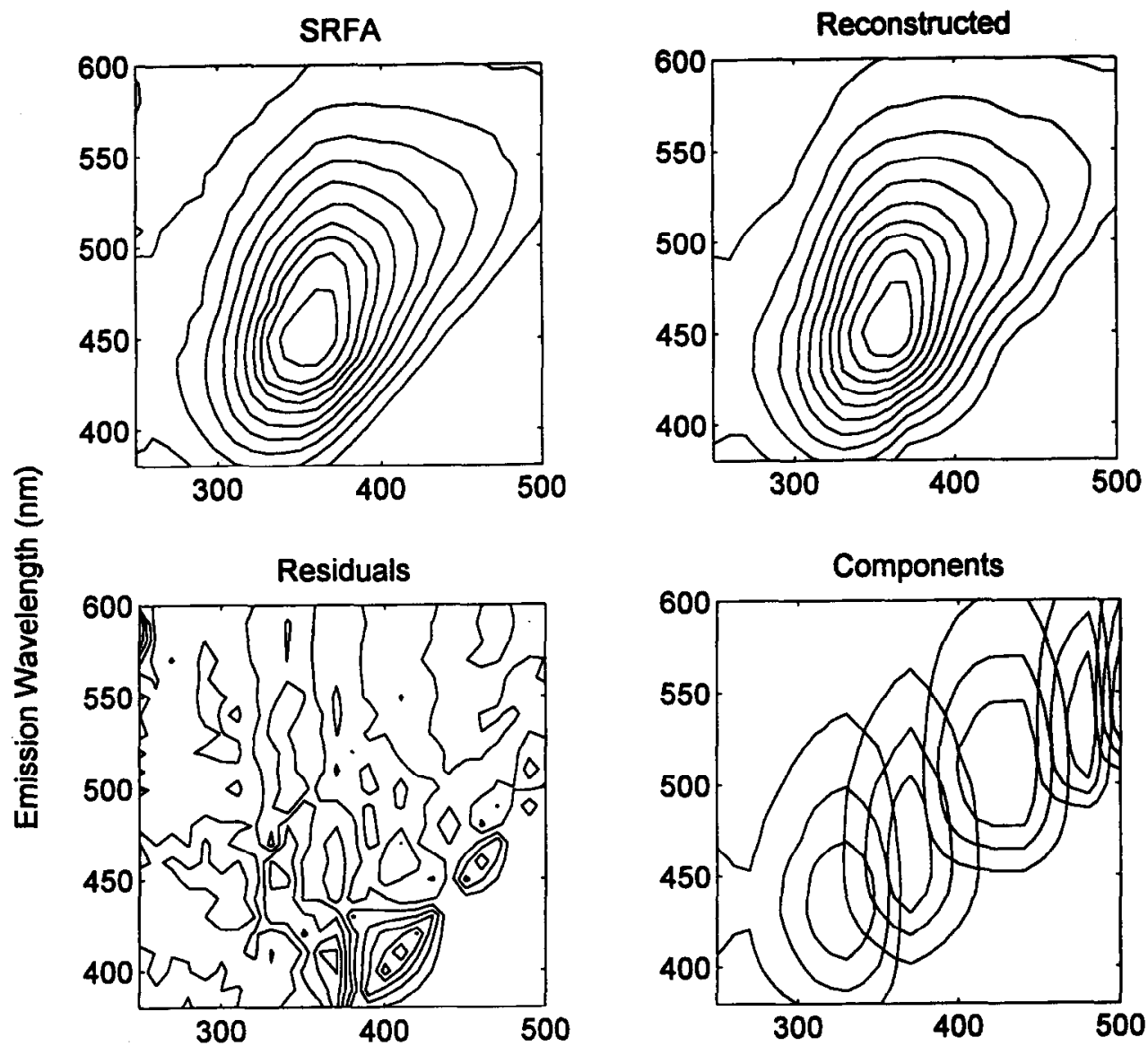

Excitation Wavelength ( $\mathrm{nm}$ )

Fig. 1. Example deconvolution of fluorescence excitation vs. emission surface. Includes original data, reconstructed data, components and residuals as contour plots. The contour intervals for the raw data and the reconstructed data are every $10 \%(0$ to $100 \%)$. The contour intervals for the components are every 33\%. The sample is Suwannee River fulvic acid (SRFA) at pH 4.36 and ionic strength $0.1 \mathrm{~mol} / \mathrm{L}$ with a concen tration of $9.45 \mathrm{mg} \mathrm{C} / \mathrm{L}$.

the concentration matrix into two matrices $Q$ and $R$, which can then be used to calculate the residual matrix. It was found that using this method, although advantageous in that it effectively reduced the number of parameters, could result in negative proportionality constants. In addition, in Smith and Kramer (1998), it was necessary to assume that the fluorescence proportionality constants for all Al-bound fluorophores were equal in order to avoid converging on negligible ligand concentrations. Both of these problems were avoided by fitting the proportionality constants along with the speciation parameters during the optimization. By fitting a linear parameter for the free ligand as well as the bound ligand, the assumption in the original Ryan-Weber equation that initial metal is negligible can be removed and, in fact, the titrations start from the total $\mathrm{Al}$ value measured in the original sample.

The objective function is then a function of $4 \mathrm{~N}$ parameters: one $\mathrm{K}^{\prime}$, one $\mathrm{L}_{\mathrm{T}}$, and two proportionality con- stants for each component. The error to be minimized is defined as the determinant of $\left(Z^{T} Z\right)$ where $Z$ is a matrix of residuals with one column for each response and one row for each set of experimental observations. Each column corresponds to the difference between the observed $F_{N}$ and the calculated $F_{N}$. This is done according to the proper Bayesian estimate of error in multiresponse systems as originally derived by Box and Draper (1965) and presented by Bates and Watts (1988). As in all nonlinear parameter fitting, good initial parameter estimates are necessary. In the fittings performed here, initial guesses for parameter fitting were determined using the usual Ryan-Weber equation (Ryan and Weber 1982) for each response separately.

The speciation at each iteration is calculated by solving for the roots of the polynomial obtained by expanding the stability constant and mass balance expressions in terms of free metal. The result is a polynomial of degree one greater then the number of ligands; 
NOM-1
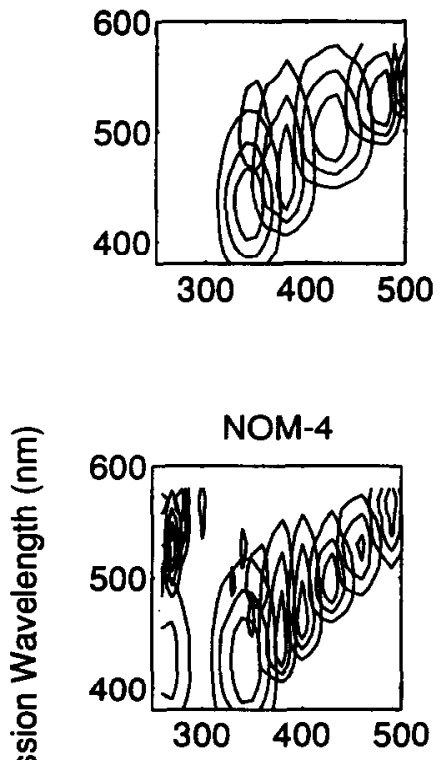

NOM-7

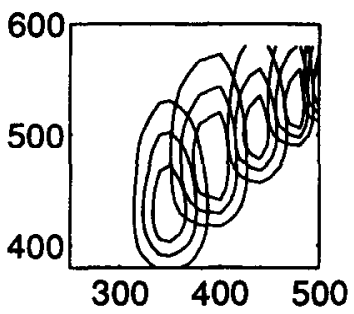

NOM-2

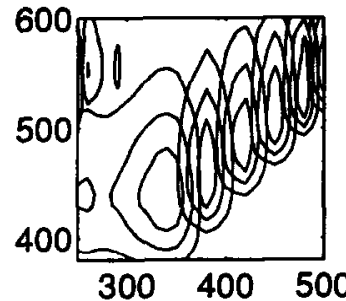

NOM-5

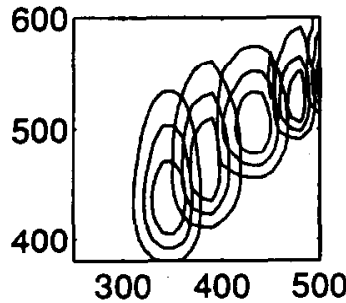

NOM-8

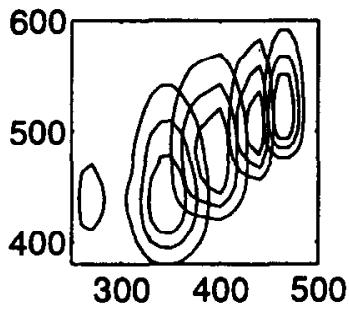

NOM-3

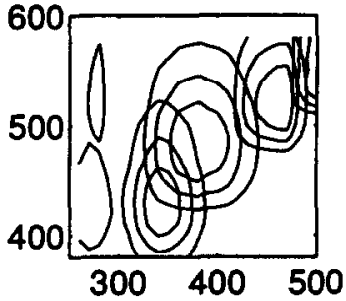

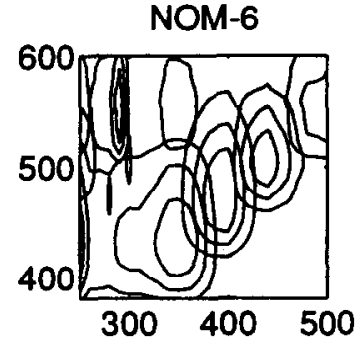

Excitation Wavelength ( $\mathrm{nm}$ )

Fig. 2. Contour plots of resolved fluorescent components from NOM RO-isolates. The contour lines indicate equal steps at $33 \%$ of the total peak height. The sample numbers correspond to the numbering scheme given in the text.

thus, for more than two ligands, there is no explicit solution to this problem, but Matlab can solve for roots quickly and efficiently. This method was selected for speciation calculations because Newton-Raphson (Benthke 1996) or the fixed point iterative scheme of Perrin and Sayce (1967) were found to be much slower.

The data was tested for linear dependencies using the method of Khuri (1990). This was done to determine if there were multiple responses with information about each component. In all cases, it was found that there were no linear dependencies among the responses. Therefore, SIMPLISMA did not find too many components. Confidence intervals were determined using the method of Kang and Bates (1990), with an approximate Hessian matrix calculated according to the method of Bates and Watts (1988). This method is an approximation but currently is the best one available to assess uncertainty in multiresponse models.

\section{RESULTS AND DISCUSSION}

An example result of spectral deconvolution, along with residuals, is shown in Fig. 1 for Suwannee River fulvic acid. The resolved components represent the data well, but there is a trend in the residuals along the Rayleigh scatter line. This is because the data here were obtained by interpolation and not actually measured. The residuals, however, are still less then $5 \%$ of the observed values. From plots like this, wavelengths corresponding to each component were selected. The peaks of most components occur where contributions from other components are negligible.

Results of deconvolution of all of the NOM samples are shown in Fig. 2. The number of components varies between 4 and 6 and, in general, the components follow a line about 50 to $80 \mathrm{~nm}$ offset from the excitation equals emission line. In addition, the short wavelength 

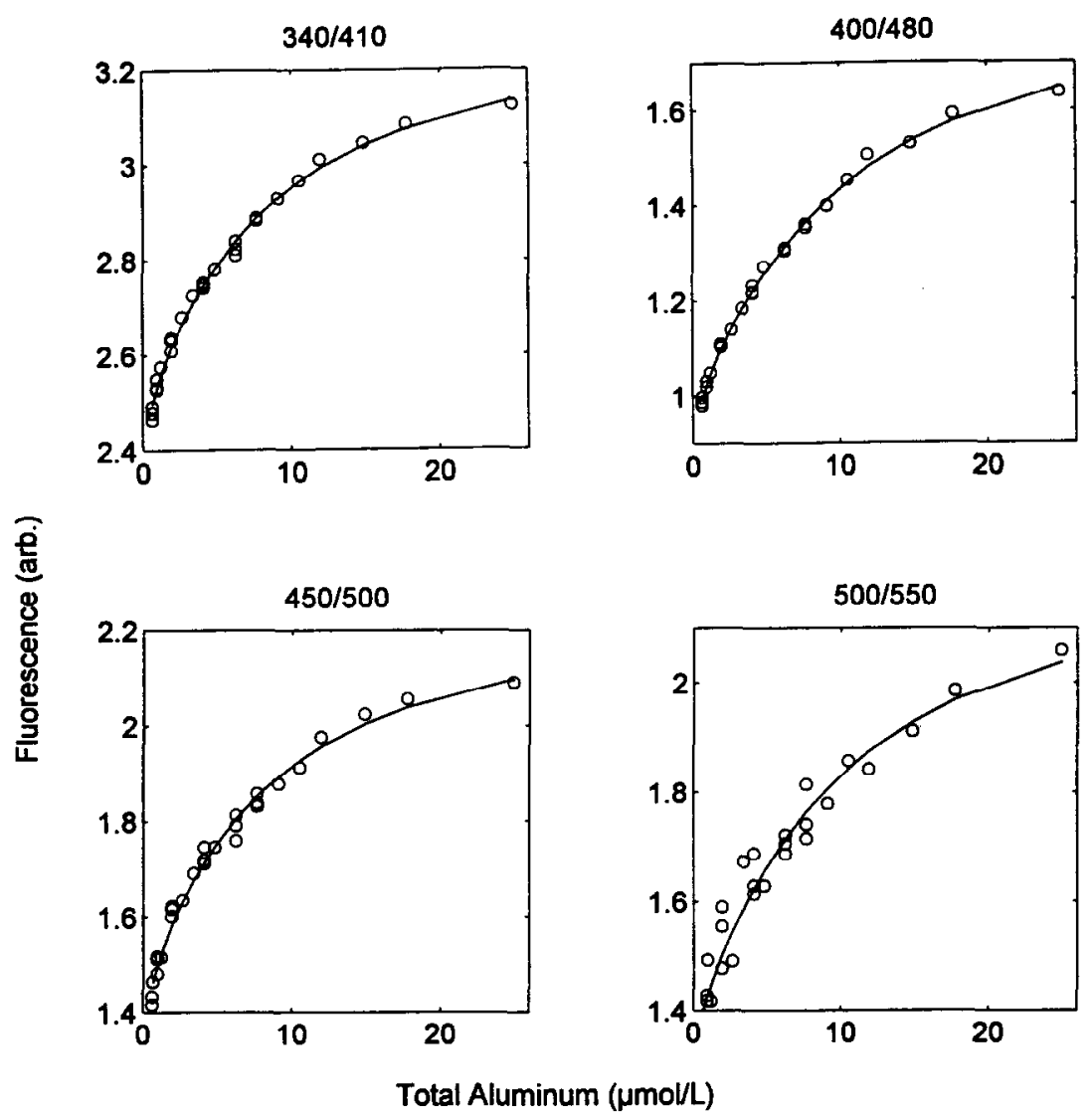

Fig. 3. Fitting results for NOM-3-RO. There are four simultaneous fluorescence responses measured as total aluminum was varied. The responses correspond to the following excitation/emission wavelengths 340/410,400/480, 450/500, and 500/550.

peak, at excitation 250 and emission $440 \mathrm{~nm}$, that is often designated a unique fluorophore (Goldberg and Weiner 1994) is a second excitation for the fluorophore emitting at around $430 \mathrm{~nm}$. On addition of aluminum, the total fluorescence surfaces were observed to change. Results observed were similar to those reported by Blaser et al. 1999. Upon deconvolutions of the surfaces with added $\mathrm{Al}$, the positions of the components varied only slightly, but the fluorescence intensity increased. This is not surprising because aluminum generally enhances fluorescence (Smith and Kramer 1998; Luster et al. 1996).

The spring and fall sampling of Helerudmyra (NOM2 and NOM-9) show differences. The most notable differences are that the spring sample has more components and the fall sample has a short wavelength component, around $290 \mathrm{~nm}$ excitation. This indicates that the nature of the organic matter changes seasonally with more complex (more components) organic matter in the spring. NOM-1, 2, and 3, which are along the Trehørningen water course in the order listed, are compared. The nature of the organic matter changes moving from NOM-1 to NOM-3; there are five com- ponents, then six, and finally just four components. NOM-7 and 8 are from an unlimed and a limed catchment, respectively. These samples are similar, except the unlimed catchment has a fluorophore not observed in the limed catchment.

Multiresponse parameter fitting was performed on simultaneous titration data obtained for each of the resolved components. An example of fitting results is shown in Fig. 3. The calculated and observed responses closely match, and the residuals are distributed randomly about the best fit line. All four responses were fit simultaneously as a function of four stability constants, four ligand concentrations, and eight fluorescence proportionality constants.

The results of parameter fitting for all samples are summarized in Fig. 4 for $\log \mathrm{K}^{\prime}$ and, in Fig. 5, for the total ligand concentrations. The fitted parameters here do not necessarily represent actual thermodynamic binding sites, and the high ionic strength used (0.1) to maintain constant activity coefficients is not representative of the natural samples. The open bars correspond to RO-isolates and the filled bars correspond to $\mathrm{EV}$-isolates. The sample numbers correspond to the 
I

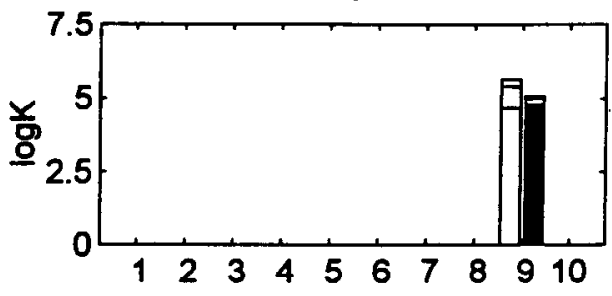

III
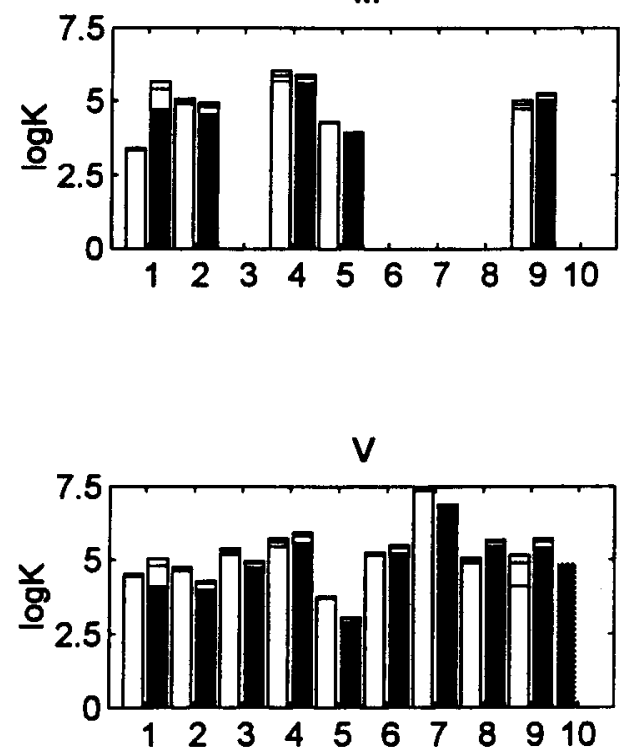

II

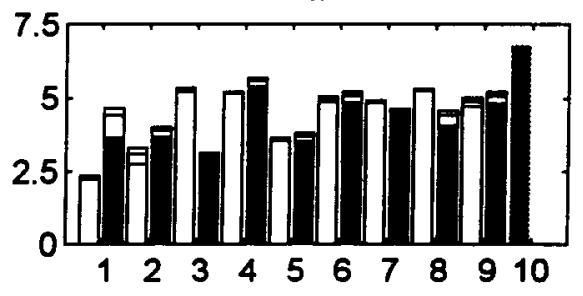

$\mathbf{N}$
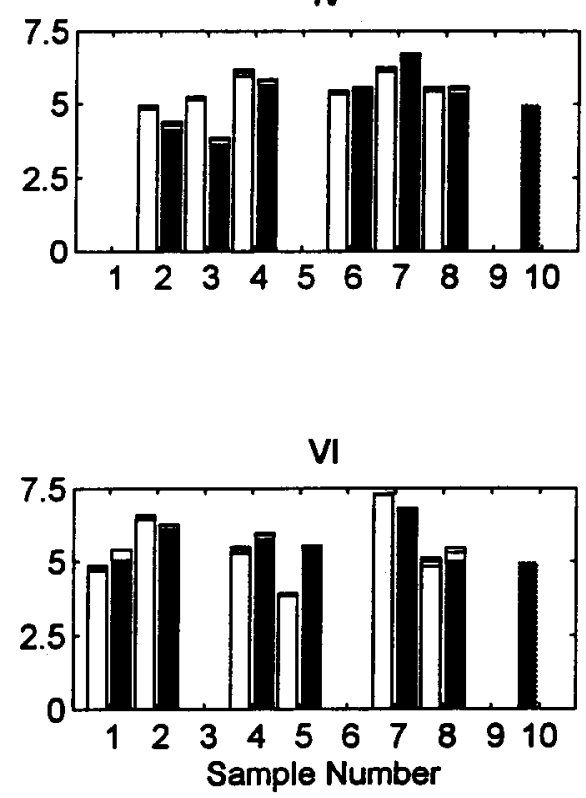

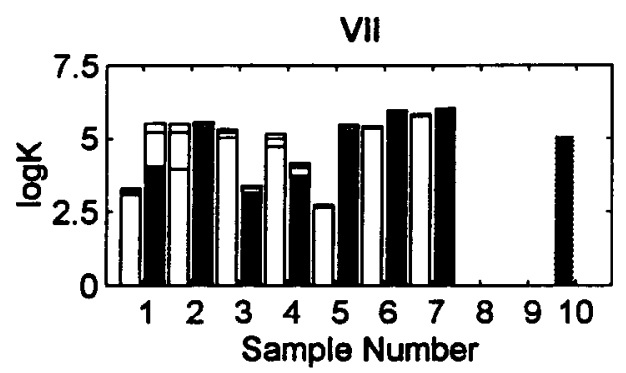

Fig. 4. Stability constants $\left(\log \mathrm{K}^{\prime}\right)$ vs. NOM sample site for each of seven proposed fluorophores. The RO-isolates are indicated by open bars and the EV-isolates by filled bars. The error bars correspond to approximate $95 \%$ confidence regions.

numbering scheme given in the methods section. The standard errors are indicated as error bars. In general, the standard errors on the $\log \mathrm{K}^{\prime}$ values are less then 0.2 of a $\log$ unit and the $\mathrm{L}_{\mathrm{T}}$ standard errors are less then $5 \%$ of the best fit value. The linear fluorescence proportionality constants are not shown because, although they are physically real parameters, they are not comparable between titrations. This is because no external calibra- tions, using standards, were performed to correct for changes in instrument output on different days.

Overall, most of the constants are around $\log \mathrm{K}^{i}$ of 4.5-5.5 with some weaker sites around 2.5-3.5 and some stronger sites near 7 . The middle sites can be interpreted as carboxylic sites with an ortho hydroxy group. This corresponds to salicylic acid like sites; at pH 4.36, salicylic acid has a conditional constant of 5.5. 

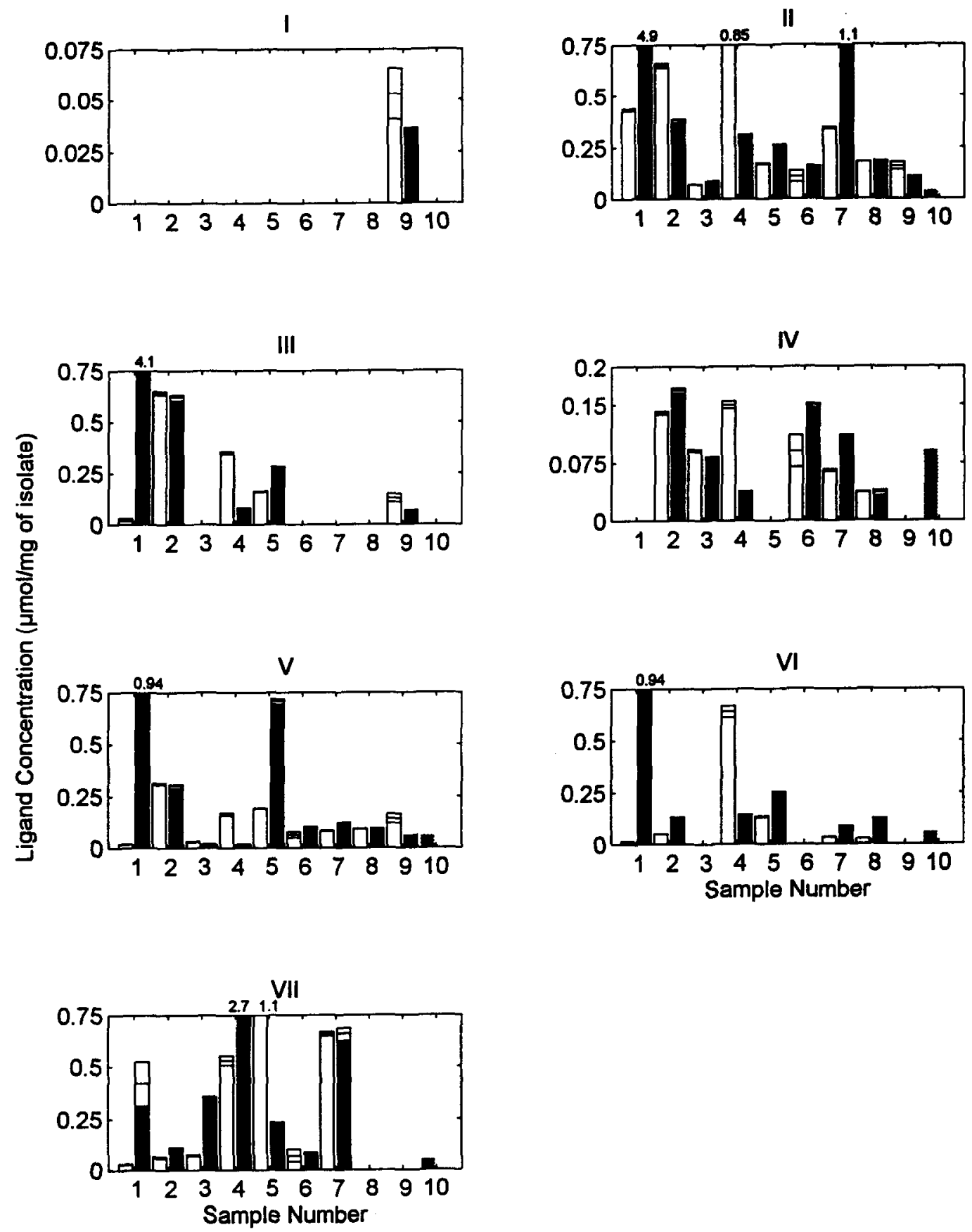

Fig. 5. Ligand concentrations vs. NOM sample site for each of seven proposed fluorophores. The RO-isolates are indicated by open bars and the VE-isolates by filled bars. The error bars correspond to approximate $95 \%$ confidence regions.

This is calculated from constants given by Martell et al. (1990). The weaker site could be a single carboxylic site without a stabilizing ortho hydroxyl group. The strongest sites are more difficult to interpret, and, at present, not even a tentative model ligand can be proposed, although similar values have been observed before. In Luster et al. (1996), a logK' value of 8.5 was observed for Juniper leaf litter extract using fluorescence and the Ryan-Weber equation, and Pott et al.
(1985) observed a value of 6.8 using a cation exchange method and Aldrich humic acid.

From the fluorescence surface, the fluorophores can be classified into seven different classes. Figure 6 shows where model compounds are observed to fluoresce. Superimposed on this is where the observed fluorophore classes fluoresce. The fluorophores are classified according to the excitation-emission groupings in Table 1. 

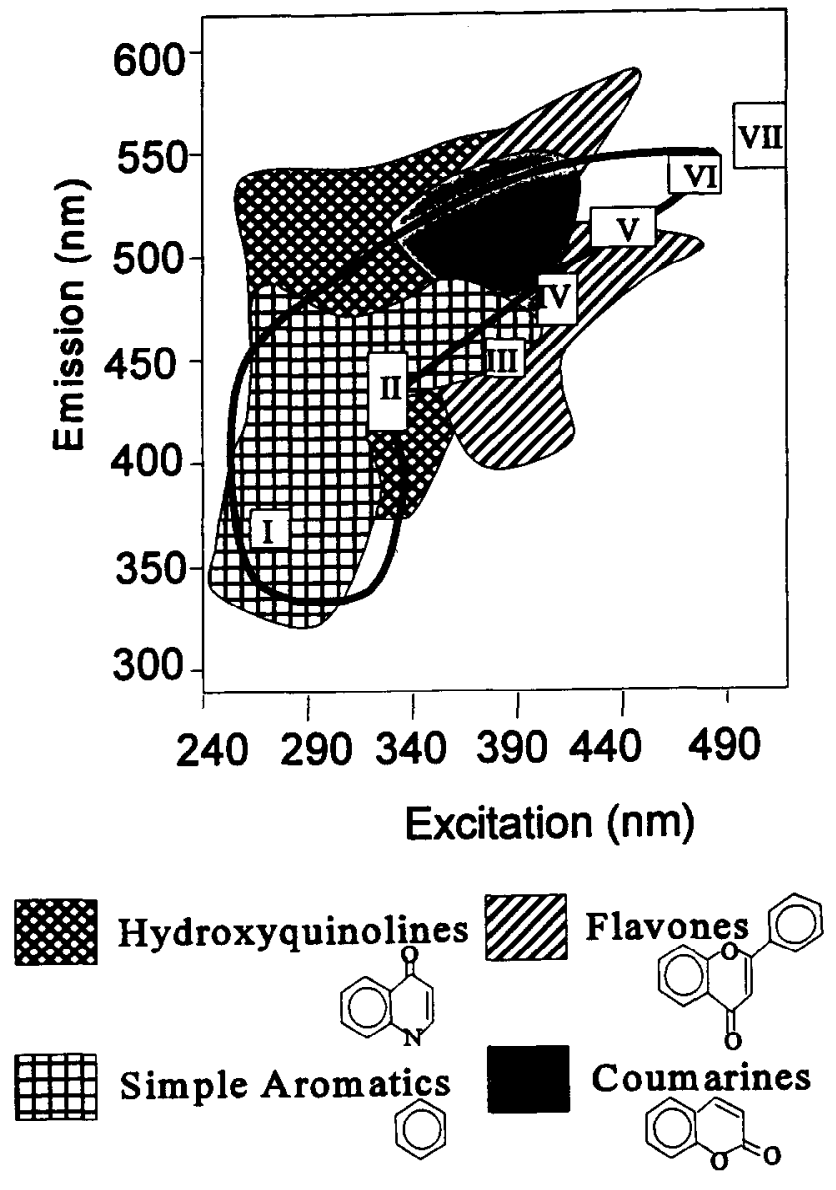

NOM

Fig. 6. Regions on an excitation vs. emission fluorescence surface that selected model compounds fluoresce. The regions indicated with boxes represent the seven classes of fluorphores observed in this study. The Roman numerals correspond to the wavelength classes given in Table 1 . The solid outline corresponds to the region where NOM is observed to fluoresce from a survey of the literature (references are given in the text).

The data used to generate Fig. 6 came from a variety of sources. Data for hydroxyquinolines came from Williams (1959); data for coumarines and flavones from Wolfbeis (1985); and data for simple aromatic compounds came from Wolfbeis (1985) and Williams (1959). Fluorescence of NOM was compiled from Miano et al. (1988); Coble et al. (1990); Senesi (1990); Shotyk and Sposito (1990); Belin et al. (1993); Tam and Sposito (1993); De Souza Sierra et al. (1994); Provenzano and Sposito (1994); and Luster et al. (1996). The NOM samples include unfractionated water, humic and fulvic acids as well as leaf litter extracts.
Table 1. Classification scheme for fluorophores in NOM.

\begin{tabular}{lcc}
\hline Class & Excitation range $(\mathrm{nm})$ & Emission range $(\mathrm{nm})$ \\
\hline I & 270 & 390 \\
II & $330-340$ & $410-450$ \\
III & $370-390$ & $440-460$ \\
IV & $400-420$ & $460-480$ \\
V & $430-450$ & $500-520$ \\
VI & $460-480$ & $520-540$ \\
VII & $490-500$ & $540-570$ \\
\hline
\end{tabular}

The components identified here fall into most of the regions of the map. Component $I$ is in the simple aromatic region. Component II is in both simple aromatics and hydroxyquinoline regions. Component III is in the flavone and simple aromatics region. Component IV is in the flavone and coumarine regions. Component $\mathrm{V}$ is in the flavone region. The remaining two components fall outside the range of values observed for these selected model compounds. This is not surprising because of the lack of summary data for model compounds.

Figure 6 is only intended to give ideas of possible fluorophores and should not be interpreted too literally. The values used to generate the figure came from a wide variety of instruments and mostly without corrections. Also, most investigators did not observe full excitation vs. emission surfaces, rather they used one dimensional excitation or emission slices of the surface; thus, the position of the maxima are only approximate. Still, the figure serves to give a broad idea of possible fluorophores in NOM and where they might fluoresce.

Table 2 summarizes the classes of fluorophores along with the observed $\log \mathrm{K}^{\prime}$ and $\mathrm{L}_{\mathrm{T}}^{\prime}$ values found in the NOM samples. The fitting results are somewhat dependent on the isolation method. In particular, NOM-1 and 3 show dramatic differences in best fit parameter values. Stability constants for fluorophores II, III, and VII are 2 orders of magnitude different in both cases, except in NOM-1, the EV sample is higher and, in NOM-3, the RO sample is higher. The RO vs. EV stability constants for the remaining sites agree within an order of magnitude and are generally within 0.5 of a log unit or less.

The binding capacities (Fig. 5) look more variable then the $\log \mathrm{K}^{\prime}$ values, but this is because they are not displayed on a log scale. Generally, the differences are less then $50 \%$ with no consistent higher or lower values between RO and EV samples. Again, NOM-1 shows 
Table 2. Summary of fluorophores in NOM.

\begin{tabular}{|c|c|c|c|c|c|c|c|}
\hline \multirow{2}{*}{$\begin{array}{l}\text { NOM } \\
\text { Sample }^{a}\end{array}$} & \multicolumn{7}{|c|}{$\log \mathrm{K}^{\prime} / \mathrm{L}_{\mathrm{T}}^{\prime}(\mathrm{mmol} / \mathrm{mg}$ of isolate) for indicated class of fluorophore } \\
\hline & I & II & III & IV & V & VI & VII \\
\hline 1-RO & & $2.3 / 0.43$ & $3.4 / 0.025$ & & $4.5 / 0.019$ & $4.8 / 0.014$ & $3.2 / 0.028$ \\
\hline 1-VE & & $4.4 / 4.9$ & $5.4 / 4.1$ & & $4.8 / 0.94$ & $4.8 / 0.94$ & $5.2 / 0.42$ \\
\hline 2-RO & & $3.1 / 0.65$ & $5.0 / 0.64$ & $4.9 / 0.14$ & $4.7 / 0.31$ & $6.5 / 0.049$ & $5.2 / 0.061$ \\
\hline 2-VE & & $3.9 / 0.38$ & $4.8 / 0.62$ & $4.3 / 0.17$ & $4.2 / 0.30$ & $6.2 / 0.13$ & $5.5 / 0.11$ \\
\hline 3-RO & & $5.3 / 0.071$ & & $5.2 / 0.091$ & $5.3 / 0.03$ & & $5.2 / 0.072$ \\
\hline $3-\mathrm{VE}$ & & $3.1 / 0.089$ & & $3.8 / 0.082$ & $4.9 / 0.018$ & & $3.3 / 0.35$ \\
\hline 4-RO & & $5.2 / 0.85$ & $5.9 / 0.35$ & $6.1 / 0.15$ & $5.6 / 0.16$ & $5.4 / 0.64$ & $5.0 / 0.53$ \\
\hline 4-VE & & $5.6 / 0.31$ & $5.8 / 0.082$ & $5.8 / 0.038$ & $5.8 / 0.018$ & $5.9 / 0.14$ & $4.0 / 2.7$ \\
\hline 5-RO & & $3.6 / 0.17$ & $4.3 / 0.16$ & & $3.7 / 0.19$ & $3.9 / 0.13$ & $2.7 / 1.1$ \\
\hline 5 -VE & & $3.7 / 0.26$ & $3.9 / 0.28$ & & $3.0 / 0.71$ & $5.5 / 0.25$ & $5.4 / 0.23$ \\
\hline 6-RO & & $5.0 / 0.11$ & & $5.4 / 0.09$ & $5.2 / 0.062$ & & $5.4 / 0.070$ \\
\hline 6-VE & & $5.1 / 0.16$ & & $5.5 / 0.15$ & $5.4 / 0.10$ & & $5.9 / 0.086$ \\
\hline 7-RO & & $4.9 / 0.34$ & & $6.2 / 0.065$ & $7.4 / 0.081$ & $7.3 / 0.032$ & $5.8 / 0.66$ \\
\hline $7-\mathrm{VE}$ & & $4.6 / 1.1$ & & $6.7 / 0.11$ & $6.9 / 0.12$ & $6.8 / 0.086$ & $6.0 / 1.2$ \\
\hline 8-RO & & $5.3 / 0.18$ & & $5.5 / 0.037$ & $5.0 / 0.090$ & $5.0 / 0.025$ & \\
\hline 8-VE & & $4.4 / 0.54$ & & $5.5 / 0.16$ & $5.6 / 0.14$ & $5.3 / 0.12$ & \\
\hline 9-RO & $5.4 / 0.053$ & $4.9 / 0.16$ & $4.9 / 0.13$ & & $4.9 / 0.14$ & & \\
\hline 9-VE & $5.0 / 0.036$ & $5.1 / 0.11$ & $5.2 / 0.071$ & & $5.6 / 0.06$ & & \\
\hline 10 & & $6.8 / 0.041$ & & $5.0 / 0 / 092$ & $4.9 / 0.057$ & $5.0 / 0.057$ & $5.1 / 0.054$ \\
\hline
\end{tabular}

a The number corresponds the NOM-isolate from the NOM-typing project and 10 corresponds to Suwannee River fulvic acid.

the greatest differences, but NOM-3 $\mathrm{L}^{\prime}{ }_{\mathrm{T}}$ values agree better between RO- and EV-isolates then the $\log \mathrm{K}^{\prime}$ values.

The seven different fluorophores can be compared between sites as well. The binding strength of each fluorophore is not the same for the different sampling sites. Thus, the fluorescent group might be similar between sites, because the wavelengths are the same, but the attached binding site might be different. In addition, effective binding strength can be reduced by competition with other metals, such as $\mathrm{Cu}$; the constants reported here are conditional. In addition, if the initial concentration of $\mathrm{Al}$ saturated strong ligand sites then these would not be observed using this method.

Fluorophore I only occurs in NOM-9; this demonstrates that seasonal differences can be resolved by this method because the same sampling site in the spring (NOM-2) does not show this fluorophore. Fluorophore II occurs in all samples and generally has $\log \mathrm{K}^{\prime}$ values around 5 except NOM-5 is weaker $(\sim 4)$ and Suwannee River fulvic acid is stronger (6.8). Fluorophore III occurs in NOM-1, 2, 4, 5, and 9. The $\log \mathrm{K}^{\prime}$ values vary around $5 \pm 1$ and again NOM-5 has the lowest value.
Fluorophore IV occurs in NOM-2, 3, 4, 7, 8, and in Suwannee River fulvic acid. The $\log K^{\prime}$ values vary between 3.8 and 6.7 with NOM-6, 8, and Suwannee River fulvic acid giving similar values around 5 but NOM-7 has a value of 6.8 and NOM-2 and 3 have similar values around 4. Fluorophore $\mathrm{V}$ occurs in all samples and has values mostly around 5, except NOM-7 is higher (7.4) and NOM-5 is the weakest (3.0). The rest of the NOM samples are similar to Suwannee River fulvic acid. Fluorophore VI occurs in NOM-1, 2, 4, 5, 7,8 , and in Suwannee River fulvic acid. As in the other classes, NOM-7 is the strongest (7.3) and NOM-5 is the weakest (3.9). The rest of the values are again similar to Suwannee River fulvic acid. Finally, fluorophore VII shows values mostly just above $5(\sim 5.2)$ that are similar to Suwannee River fulvic acid. NOM-5 is the weakest (2.7 in RO), except the EV-isolate yields a value of 5.4 which is similar to the rest of the samples. NOM-7 is only slightly stronger then the rest of the samples (5.8 for RO, 6.0 for EV).

Overall, NOM-7 shows stronger binding and NOM-5 shows weaker binding for a given fluorophore. The rest of the sample sites are similar to Suwannee River 
fulvic acid, showing binding strengths between 4.8 and 5.5 , except fluorophore II in Suwannee River fulvic acid has binding strengths almost 2 orders of magnitude stronger than in the rest of the samples.

\section{CONCLUSIONS}

The Norway NOM samples show different fluorescent components, with different binding strengths. There were seven different fluorescent components identified by SIMPLISMA spectral deconvolution. These seven components compare well with the fluorescence of model compounds except two components are outside the region where the model compounds reported here fluoresce. The sampling sites contain between four and six of the identified fluorophores. Seasonal differences can be resolved, as well as differences between limed and unlimed catchments.

The determined binding strengths $\left(\log \mathrm{K}^{\prime}\right)$ for the fluorophores are generally between 4.8 and 5.5 and agrec well with values for the same fluorophores in Suwannee River fulvic acid, except Suwannee River fulvic acid shows stronger binding by almost 2 orders of magnitude in 1 of the fluorophores. There were also weak sites, with $\log K^{\prime}$ between 3 and 4 as well as stronger sites with $\log \mathrm{K}^{\prime}$ values around 7 . Overall, NOM-7 showed the strongest binding constants and NOM-5 showed the weakest stability constants. The isolation method was seen to influence the results; thus, one or both of the isolation methods modify the original raw water samples to some extent.

The method presented here is able to determine differences between NOM samples and yields some qualitative information about the nature of $\mathrm{Al}$ binding sites (fluorescence properties) and quantitative information (binding constant and site densities). It is useful to be able to treat the NOM samples as a mixture of a minimum number of fluorescent binding sites (between 4 and 6 for these samples). These sites represent averaging of all of the sites within NOM and, in a broad sense, can allow comparisons between samples.

Acknowledgment - The authors would like to acknowledge the members of the NOM-Typing project organization committee. In addition, DSS would like to acknowledge an Ontario Graduate Scholarship for financial support and JRK would like to acknowledge funding from the Natural Sciences and Engineering Research Council of Canada.

\section{REFERENCES}

Bates, D.M.; Watts, D.G. Nonlinear regression analysis and its applications. New York, NY: John Wiley \& Sons; 1988.

Belin, C.; Quellec, C.; Lamotte, M.; Domach, M.M.; Simon, R. Characterization by fluorescence of the dissolved organic matter in natural water. Application to fractions obtained by tangential ultrafiltration and XAD resin isolation. Environ. Technol. 14: 1131-1144; 1993.

Benthke, C.M. Geochemical reaction modeling. New York, NY: Oxford University Press; 1996.

Blaser, P; Heim, A.; Luster, J. Total luminescence spectroscopy of NOM-typing samples and their aluminium complexes. Environ. Int. 25: 285-293; 1999.

Box, G.E.P.; Draper, N.R. The Bayesian estimation of common parameters from several responses. Biometrika 52: 355-364; 1965.

Coble, P.G.; Green, S.A.; Blough, N.V.; Gagosian, R.B. Characterization of dissolved organic matter in the Black Sea by fluorescence spectroscopy. Nature 348: 432-435; 1990.

Cronan, C.S.; Grigal, D.F. Use of calcium/aluminum ratios as indicators of stress in forest ecosystems. J. Environ. Qual. 24: 209$226 ; 1995$.

Dalibart, M. Multicomponent analysis in luminescence spectroscopy. Talanta 44: 2231-2235; 1997.

De Souza Sierra; Donard, O.F.X.; Lamotte, M.; Belin, C.; Ewald, M. Fluorescence spectroscopy of coastal and marine waters. Mar. Chem. 47: 127-144; 1994.

Gjessing, E.T.; Egeberg, P.K.; Hikedal, J.T. Natural organic matter in drinking water. The "NOM-typing project", background and basic characterization of the original water samples and NOM isolates. Environ. Int. 25: 145-159; 1999.

Goldberg, M.C.; Weiner, E.R. Fluorescence measurements of volume, shape, and fluorophore composition of fulvic acid from the Suwannee River. In: Averett, R.C.; Leenheer, J.A.; McKnight, D.M.; Thorn, K.A., eds. Water supply paper 2373. Reston, VA: U.S. Geological Survey; 1994.

Grace, A. Optimization toolbox user's guide. Natick, MA: The MathWorks, Inc.; 1992.

Guilbault, G.C. Practical fluorescence: Theory methods and techniques. New York, NY: Marcel Dekker, Inc.; 1973.

Kang, G.; Bates, D.M. Approximate inference in multiresponse regression analysis. Biometrika 77: 321-331; 1990.

Khuri, A.I. The effect of response scaling on the detection of linear dependencies among multiresponse data. Metrika 37: 217-231; 1990.

Luster, J.; Lloyd, T.I.; Sposito, G. Multi-wavelength molecular fluorescence spectrometry for quantitative characterization of copper(II) and aluminum(III) complexalion by dissolved organic matter. Environ. Sci. Technol. 30: 1565-1574; 1996.

Marschner, H. Mineral nutrition of higher plants. I ondon, Fngland: Academic Press; 1995.

Martell, A.E.; Motekaitis, R.J.; Smith, R.M. Aluminum complexes of hydroxyaliphatic and hydroxyaromatic ligands in aqueous systems - Some problems and solution. Polyhedron 9: 171-187; 1990.

Miano, T.M.; Sposito, G.; Martin, J.P. Fluorescence spectroscopy of humic substances. Soil Sci. Soc. Am. J. 52: 1016-1019; 1988.

Nieboer, E.; Gibson, B.L.; Oxman, A.D.; Kramer, J.R. Health effects of aluminum: A critical review with emphasis on aluminum in drinking water. Environ. Rev. 3: 29-81; 1995. 
Parent, L.; Twiss, M.R.; Campbell, P.G. Influences of natural dissolved organic matter on the interactions of aluminum with the microalga chlorella: A test of the free-ion model of trace metal toxicity. Environ. Sci. Technol. 30: 1713-1720; 1996.

Perrin; Sayce. Computational method to determine metal speciation in the presence of complexing ligands. Talanta 14: 833-837; 1967.

Pott, D.B.; Alberts, J.J.; Elzerman, A.W. The influence of $\mathrm{pH}$ on the binding capacity and conditional stability constants of aluminum and naturally occurring organic matter. Chem. Geol. 48: 293304; 1985.

Provenzano, M.R.; Sposito, G. Application of two-dimensional fluorescence spectroscopy to the study of pine litter in different ecosystems. In: Senesi, N.; Miano, T.M., eds. Humic substances in the global environment and implications on human health. Amsterdam: Elsevier; 1994: 335-342.

Ryan, D.K.; Weber, J.H. Fluorescence quenching titration for determination of complexing capacities and stability constants of fulvic acid. Anal. Chem. 54: 986-990; 1982.

Senesi, N. Molecular and quantitative aspects of the chemistry of fulvic acid and its interactions with metal ions and organic chemicals. Part II the fluorescence spectroscopy approach. Anal. Chim. Acta 232: 77-106; 1990.
Shotyk, W.; Sposito, G. Ligand concentration effects on aluminum complexation by a chestnut leaf litter extract. Soil Sci. Soc. Am. J. 54: 933-935; 1990.

Smith, D.S.; Kramer, J.R. Multi-site aluminum speciation with natural organic matter using multiresponse fluorescence data. Anal. Chim. Acta 363: 21-29; 1998.

Tam, S.C.; Sposito, G. Fluorescence spectroscopy of aqueous pine litter extracts: Effects of humification and aluminum complexation. J. Soil Sci. 44: 513-524; 1993.

Tucker, S.A.; Amszi, V.L.; Acree, W.E. Primary and secondary inner filtering. J. Chem. Edu. 69: A10-A12; 1992.

van Stokkum, I.H.M.; Brouwer, A.M.; van Ramesdonk, H.J.; Schere, T. Multiresponse parameter estimation and compartmental analysis of time resolved fluorescence spectra. Proc. Kon. Ned. Akad. v. Wetensch. 96: 43-68; 1993.

Williams, R.T. The fluorescence of some aromatic compounds in aqueous solution. J. Royal Institute Chem. 83: 611-626; 1959.

Windig, W.; Guilment, J. Interactive self-modeling mixture analysis. Anal. Chem. 63: 1425-1432; 1991.

Wolfbeis, O.S. Fluorescence of organic natural products. In: Schulman, S.G., ed. Molecular luminescence spectroscopy: Methods and applications - Part 1. Toronto, Canada: John Wiley and Sons; 1985. 